\title{
In Response to "Comment on Average Volume-Assured Pressure Support Modes for Hypercapnic Respiratory Failure its early use in the Emergency Department"
}

\author{
Nurfer Gören® \\ Department of Emergency, İzmir University of Economics, Medical Park Hospital, İzmir, Turkey
}

We read with great interest the Letter to the Editor entitled "Average Volume-Assured Pressure Support Modes for Hypercapnic Respiratory Failure and its Early Use in the Emergency Department." We wish to thank you for your contributions and detailed evaluation of our work.

The use of non-invasive ventilation (NIMV) as the first treatment option in the management of patients with acute respiratory failure (ARF) is increasing yearly. ${ }^{1}$ Although it is considered to be the treatment modality of choice in the management of patients with COPD exacerbations, its use in the treatment of other causes of ARF has increased significantly in recent years. In a study evaluating more than 10 million ARF cases, it was found that, while there was a $250 \%$ increase in the frequency of use in patients with COPD exacerbation within 10 years, its use in patients ARF due to other causes increased by $400 \%{ }^{2}$

Pressure support applied above PEEP during NIV administration provides a better physiological response in terms of unloading the muscle load and relieving dyspnea compared to CPAP. ${ }^{3}$ Positive pressure inspiratory support reduces the breathing effort by providing greater transpulmonary pressure during inspiration. In addition, it increases the tidal volume. ${ }^{4}$ It has been reported that using the volume-guaranteed mode provides a more significant improvement in respiratory workload. It is thought that this is due to the shorter inspiratory time and higher mean inspiratory flow in volume-guaranteed practice. ${ }^{4}$ At this point, mode selection is important considering the physiological needs of the patient during NIV application. This is especially important in medical units where NIV is applied to patients from various patient spectrums, such as the emergency department (ED). ${ }^{5}$

Average Volume-Assured Pressure Support (AVAPS) can be used in a variety of different settings ${ }^{6,7}$, and we have enrolled hypercapnic patients in our study who were admitted to the ED without differentiating the etiology of their acute hypercapnic failure. ${ }^{8}$ We aimed to simulate the real-life practice in the ED as much as possible; therefore, we did not select a specific patient group. The main reasoning behind this approach was to evaluate the daily practice of the ED, as in most scenarios, the patients admitting to the ED present with unspecified causes of ARF. As the esteemed author(s) stated, more specific results could have been obtained if this was tested in a specific patient group in this study. However, the definitive diagnosis of patients with ARF in the ED is often not clear in the initial treatment plan. In addition, our study was the first to evaluate AVAPS in the ED. For this reason, we thought that its effectiveness in general practice is more important. Furthermore, we support the idea that there is a need for studies that will evaluate its use in specific indications in future studies.

Secondly, although the authors argue that the lack of evaluation parameters for ventilator mode monitoring may have affected the results, we disagree with them. As the author stated, Carteaux et al. reported that high expired tidal volume was independently associated with NIV failure in patients with denovo respiratory failure. In this study, patients with exacerbation of chronic lung disease or cardiac failure were excluded. ${ }^{9}$ While ventilator monitoring and parameters such as exhaled tidal volume are important in patient follow-up, we do not think that not reporting this in our study affects the results as claimed by the author(s). Finally, although NIMV failure is mostly expected in the immediate and early periods ${ }^{10}$, including late period data would have improved interpretation of our secondary outcome results, as stated by the author(s). Therefore, we agree with the author(s) on this remark. In our study, we primarily aimed to evaluate NIMV outcomes from an ED perspective, and we have included this in our study's limitation section. 
We would like to extend our appreciation to the author(s) for their remarks and also agree on the fact that utilizing AVAPS in early clinical settings would yield a rapid recovery in vital parameters and level of consciousness.

\section{REFERENCES}

1. Demoule A, Girou E, Richard JC, Taillé S, Brochard L. Increased use of noninvasive ventilation in French intensive care units. Intensive Care Med. 2006;32:1747-1755. [CrossRef]

2. Walkey AJ, Wiener RS. Use of noninvasive ventilation in patients with acute respiratory failure, 2000-2009: a population-based study. Ann Am Thorac Soc 2013;10:10-17. [CrossRef]

3. Mehta S, Hill NS. Noninvasive ventilation. Am J Respir Crit Care Med. 2001;163:540577. [CrossRef]

4. Walkey AJ, Wiener RS. Use of noninvasive ventilation in patients with acute respiratory failure, 2000-2009: a population-based study. Ann Am Thorac Soc 2013;10:10-17. [CrossRef]

5. Antro C, Merico F, Urbino R, Gai V. Non-invasive ventilation as a first-line treatment for acute respiratory failure: "real life" experience in the emergency department. Emerg Med J. 2005;22:772-777. [CrossRef]
6. Murphy PB, Davidson C, Hind MD, et al. Volume targeted versus pressure support non-invasive ventilation in patients with super obesity and chronic respiratory failure: a randomised controlled trial. Thorax. 2012;67:727-734. [CrossRef]

7. Briones Claudett KH, Briones Claudett M, Chung Sang Wong M, et al. Noninvasive mechanical ventilation with average volume assured pressure support (AVAPS) in patients with chronic obstructive pulmonary disease and hypercapnic encephalopathy. BMC Pulm Med. 2013;13:12. [CrossRef]

8. Gören NZ, Şancı E, Ercan Coşkun FF, et al. Comparison of BPAP S/T and Average Volume-Assured Pressure Support Modes for Hypercapnic Respiratory Failure in the Emergency Department: A Randomized Controlled Trial. Balkan Med J. 2021; 38:265-271. [CrossRef]

9. Carteaux G, Millán-Guilarte T, De Prost N, Razazi K, Abid S, Thille AW, Schortgen F, Brochard L, Brun-Buisson C, Mekontso Dessap A. Failure of Noninvasive Ventilation for De Novo Acute Hypoxemic Respiratory Failure: Role of Tidal Volume. Crit Care Med. 2016;44:282-290. [CrossRef]

10. Ozyilmaz E, Ugurlu AO, Nava S. Timing of noninvasive ventilation failure: causes, risk factors, and potential remedies. BMC Pulm Med. 2014;14:19. [CrossRef] 